\title{
Objectively-Measured Impulsivity and Attention-Deficit/Hyperactivity Disorder (ADHD): Testing Competing Predictions from the Working Memory and Behavioral Inhibition Models of ADHD
}

\author{
Joseph S. Raiker • Mark D. Rapport • \\ Michael J. Kofler • Dustin E. Sarver
}

Published online: 21 January 2012

(C) Springer Science+Business Media, LLC 2012

\begin{abstract}
Impulsivity is a hallmark of two of the three DSM-IV ADHD subtypes and is associated with myriad adverse outcomes. Limited research, however, is available concerning the mechanisms and processes that contribute to impulsive responding by children with ADHD. The current study tested predictions from two competing models of ADHD — working memory (WM) and behavioral inhibition (BI) - to examine the extent to which ADHD-related impulsive responding was attributable to model-specific mechanisms and processes. Children with ADHD $(n=21)$ and typically developing children $(n=20)$ completed laboratory tasks that provided WM (domain-general central executive [CE], phonological/visuospatial storage/rehearsal) and BI indices (stop-signal reaction time [SSRT], stop-signal delay, mean reaction time). These indices were examined as potential mediators of ADHD-related impulsive responding on two objective and diverse laboratory tasks used commonly to assess impulsive responding (CPT: continuous performance test; VMTS: visual match-to-sample). Bias-corrected, bootstrapped mediation analyses revealed that $\mathrm{CE}$ processes significantly attenuated between-group impulsivity differences,
\end{abstract}

Joseph S. Raiker, Department of Psychology, University of Central Florida; Mark D. Rapport, Department of Psychology, University of Central Florida; Michael J. Kofler, Department of Psychology, University of Central Florida; Dustin E. Sarver, Department of Psychology, University of Central Florida

J. S. Raiker · M. D. Rapport • M. J. Kofler · D. E. Sarver Department of Psychology, University of Central Florida, Orlando, FL, USA

M. D. Rapport ( $\bowtie)$

Children's Learning Clinic-IV, Department of Psychology,

University of Central Florida,

P.O. Box 161390, Orlando, FL 32761, USA

e-mail: mdrapport@gmail.com such that the initial large-magnitude impulsivity differences were no longer significant on either task after accounting for ADHD-related CE deficits. In contrast, SSRT partially mediated ADHD-related impulsive responding on the CPT but not VMTS. This partial attenuation was no longer significant after accounting for shared variance between CE and SSRT; CE continued to attenuate the ADHD-impulsivity relationship after accounting for SSRT. These findings add to the growing literature implicating $\mathrm{CE}$ deficits in core ADHD behavioral and functional impairments, and suggest that cognitive interventions targeting $\mathrm{CE}$ rather than storage/rehearsal or $\mathrm{BI}$ processes may hold greater promise for alleviating ADHDrelated impairments.

Keywords ADHD · Impulsive responding · Working memory · Behavioral inhibition · Commission errors . Executive functions

The ability to inhibit impulses is one of the earliest and most ubiquitous societal demands placed on children. Deficits in this ability are particularly salient in children with attentiondeficit/hyperactivity disorder (ADHD) and are a primary feature of the disorder (APA 2000). As a core component, the impulsivity construct refers to diverse actions that are performed without sufficient forethought and frequently result in undesirable consequences, including errors on academic assignments and cognitive tasks.

Identifying underlying mechanisms and processes that contribute to impulsive behavior in children with ADHD is imperative given its high heritability (Nikolas and Burt 2010), developmental continuity, and association with undesirable consequences throughout life. During childhood, adverse consequences associated with impulsive behavior 
include an increased risk for mishaps (Palili et al. 2011), excessive errors on schoolwork and homework (Zentall 1993), peer relational difficulties (Diamantopoulou et al. 2007), and higher rates of oppositional defiant symptoms (Burns and Walsh 2002). In later years, its continuation portends poor financial planning and lower SES (Moffitt et al. 2011), deficient driving behavior (Barkley 2004), earlier/ riskier sexual activity, unstable relationships, and impaired occupational functioning (Barkley et al. 2006), as well as increased risk for substance use/abuse (Moffitt et al. 2011; Molina et al. 1999; Rodriguez et al. 2008), antisocial behavior (Babinski et al. 1999), and adult criminal conviction (Moffitt et al. 2011).

Impulsive behavior in children with ADHD is quantified objectively by measuring commission errors on laboratorybased tasks that require children to evaluate stimuli in an efficient manner. Commission errors refer to discrete instances in which children respond incorrectly to non-target stimuli, and demonstrate moderate convergent validity with diverse indices of impulsivity ( $r=0.20$ to 0.45 ). These indices include parent ratings (Avila et al. 2004; Barkley 1991; Nigg et al. 1996; Olson et al. 1999), teacher ratings (Barkley 1991; Brewis 2002; Halperin et al. 1991; Halperin et al. 1988; Klee and Garfinkel 1983), clinical diagnostic interviews (Epstein et al. 2003), direct observations of impulsive behavior while completing academic assignments (Barkley 1991), and composite indices of direct observations, parent/ teacher reports, and self-report (Moffitt et al. 2011).

Examples of laboratory tasks designed to measure impulsive responding (i.e., commission errors) in children with ADHD include continuous performance tests (CPTs) and visual match-to-sample tasks. CPT variants (e.g., vigilance, $n$-back tasks) characteristically require children to respond to infrequently occurring, phonologically encoded stimuli (e.g., letters or numbers; Nichols and Waschbusch 2004), whereas visual match-to-sample (VMTS) tasks require rapid discrimination among visuospatial stimuli (Carlson et al. 1986; Inoue et al. 1998; Rapport et al. 1996). Impulsive responding on these tasks may reflect distinct or combined underlying executive function (EF) deficits due to cognitive processing differences associated with how task stimuli are encoded (phonologically, visuospatially), and the degree of inhibitory control and working memory processes required by the tasks (Denney et al. 2005; Klein et al. 2006). To date, however, no study has investigated whether deficiencies in specific executive functions mediate ADHD-related commission errors on paradigm-specific tasks.

Executive functions involve frontal/prefrontal cortical areas that allow for the planning, regulation, execution, and inhibition of behavior (for a review, see Willcutt et al. 2005). Behavioral inhibition (BI) and working memory (WM) have emerged as two of the most promising executive functions for explaining a wide array of ADHD symptoms based on recent meta-analytic reviews (Willcutt et al. 2005), empirical studies (Holmes et al. 2010), comprehensive reviews (Sergeant et al. 2002), and factor analytic results of executive functioning deficits associated with the disorder (Sonuga-Barke et al. 2010). Both candidate processes are featured in contemporary models of ADHD (Barkley 2006; Rapport et al. 2008a), but the models diverge significantly regarding the primacy of these processes, and the mechanisms through which these executive function deficits may result in excessive commission errors.

Behavioral inhibition (BI) is hypothesized as a cognitive process that sub-serves behavioral regulation and specific executive functions (Barkley 2006), and underlies the ability to withhold or stop an on-going response (Schachar et al. 2000). ADHD-related excessive commission errors are hypothesized to occur by means of two interrelated pathways. The first pathway reflects a direct impact of ADHD-related deficient inhibitory processes on impulsive errors such that motor responses initiated in response to prepotent stimuli are not overridden or terminated following commands from frontal/pre-frontal cortical areas (Aman et al. 1998; Aron and Poldrack 2005). The second pathway reflects indirect effects of ADHD-related deficient inhibitory processes on working memory, one of the four executive functions described by Barkley (2006) that may be affected adversely secondary to primary BI deficits. Specifically, deficient inhibitory processes fail to prevent extraneous information from entering WM, resulting in difficulty maintaining task goals and stimulus configurations due to interference (Barkley 2006; Brocki et al. 2008). Finally, the excessive commission errors exhibited by children with ADHD may reflect both direct and indirect influences of BI deficiencies.

The functional working memory model of ADHD, in contrast, posits that impulsive responding on cognitive tasks (i.e., commission errors) is a byproduct of deficient working memory processes (Rapport et al. 2008b). Working memory refers to a limited capacity system for the temporary storage, rehearsal, and manipulation of internally-held information for use in guiding behavior. Extensive evidence reveals two distinct working memory subsystems, phonological and visuospatial, that are overseen by a domain-general attentional controller termed the central executive (Baddeley 2007). Phonological and visuospatial working memory refer to the central executive working in conjunction with the verbal and visuospatial storage/rehearsal mechanisms, respectively, to process internally-held, modality-specific information. Working memory deficits are expected to result in impulsive responding on laboratory tasks by means of three interrelated processes. The first of these processes reflects deficient storage/rehearsal capacity that may cause children with ADHD to prematurely forget task rules and instructions needed for successful performance. The second process reflects an inability to hold multiple stimuli 
simultaneously or for the duration necessary to make accurate comparisons. Finally, deficient central executive processing-which is particularly impaired in children with ADHD (Kofler et al. 2010) - may result in failure to effectively process and update information within working memory, or result in internal interference from task-irrelevant stimuli concurrently held within working memory (Rapport et al. 2008b).

The current study is the first to test competing predictions stemming from the BI and WM models regarding the underlying mechanisms responsible for children's impulsive responding (i.e., commission errors) on tasks used commonly in laboratory and clinical settings. For the behavioral inhibition model, BI processes were hypothesized to partially or fully mediate the relationship between diagnostic group membership (ADHD, typically developing children) and task-related impulsive responses on both tasks to the extent that performance on the two tasks relies on these processes for successful execution. BI processes were also expected to exert indirect effects on task-related impulsive responses to the extent that hypothesized BI deficits weaken working memory processes needed for successful task performance. In addition, any mediating effects of BI on the magnitude of between-group (ADHD, typically developing children) impulsivity differences should remain significant after removing WM influences, whereas any WM mediating effect should no longer be significant after removing BI influences.

For the working memory model, increased ADHD-related impulsive responding on both tasks (CPT, VMTS) was expected to be fully mediated by WM central executive processes to the extent that task performance relies on these processes for successful execution. WM central executive processes were also hypothesized to exert greater magnitude effects relative to both WM storage/rehearsal subcomponents given the larger magnitude central executive relative to storage/rehearsal deficits associated with ADHD (e.g., Kofler et al. 2010; Rapport et al. 2008a) The hypothesized partial mediating effects of phonological and visuospatial storage/rehearsal, however, were expected to be modality specific based on the assumptions that children process letters phonologically during the CPT, and utilize their visuospatial subsystem to identify complex matching stimuli during the VMTS.

Finally, the WM model views inhibited behavior as a response to environmental events and postulates that these events require a priori registration and processing by WM before they can be acted upon (Rapport et al. 2001). As a result, any mediating effects of WM on the magnitude of between-group impulsivity differences were expected to remain significant after removing $\mathrm{BI}$ influences. In addition, any BI mediating influences on impulsive responding should no longer be apparent after removing WM influences.

\section{Method}

\section{Participants}

The sample consisted of 41 boys aged 8 to 12 years, recruited by or referred to the Children's Learning Clinic (CLC-IV) through community resources (e.g., pediatricians, community mental health clinics, school system personnel, self-referral). The CLC-IV is a research-practitioner training clinic known to the surrounding community for conducting developmental and clinical child research and providing pro bono comprehensive diagnostic and psychoeducational services. Its client base consists of children with suspected learning, behavioral or emotional problems, as well as typically developing children (those without a suspected psychological disorder) whose parents agree to have them participate in developmental/clinical research studies. A psychoeducational report was provided to the parents of all participants. All parents and children gave their informed consent/assent prior to participating in the study, and approval from the university's Institutional Review Board was obtained prior to the onset of data collection. Two groups of children participated in the study: children with ADHD, and typically developing children without a psychological disorder.

\section{Group Assignment}

All children and their parents participated in a detailed, semi-structured clinical interview using the Kiddie Schedule for Affective Disorders and Schizophrenia for School-Aged Children (K-SADS). The K-SADS assesses onset, course, duration, severity, and impairment of current and past episodes of psychopathology in children and adolescents based on DSM-IV criteria. Its psychometric properties are well established, including interrater agreement of 0.93 to 1.00 , test-retest reliability of 0.63 to 1.00 , and concurrent (criterion) validity between the K-SADS and psychometrically established parent rating scales (Kaufman et al. 1997).

Twenty-one children met the following criteria and were included in the ADHD-Combined Type group: (1) an independent diagnosis by the CLC's directing clinical psychologist using DSM-IV criteria for ADHD-Combined Type based on K-SADS interview with parent and child which assesses symptom presence and severity across home and school settings; (2) parent ratings of at least $2 S D$ s above the mean on the Attention-Deficit/Hyperactivity Problems DSM-Oriented scale of the Child Behavior Checklist (CBCL; Achenbach and Rescorla 2001), or exceeding the criterion score for the parent version of the ADHD-Combined subtype subscale of the Child Symptom Inventory-4: Parent Checklist (CSI-P; Gadow et al. 2004); and (3) teacher ratings of at least 2 SDs above the mean on the Attention-Deficit/Hyperactivity Problems DSM-Oriented scale of the Teacher Report Form (TRF; 
Achenbach and Rescorla 2001), or exceeding the criterion score for the teacher version of the ADHD-Combined subtype subscale of the Child Symptom Inventory-4: Teacher Checklist (CSI-T; Gadow et al. 2004). The CBCL, TRF, and CSI are among the most widely used behavior rating scales for assessing psychopathology in children. Their psychometric properties are well established (Rapport et al. 2008b). 33.3\% of the children in the ADHD group were comorbid for Oppositional Defiant Disorder (ODD). None of the children were comorbid for additional DSM-IV childhood disorders.

Twenty children met the following criteria and were included in the typically developing group: (1) no evidence of any clinical disorder based on parent and child K-SADS interview; (2) normal developmental history by maternal report; (3) ratings within $1.5 \mathrm{SDs}$ of the mean on all CBCL and TRF scales; and (4) parent and teacher ratings within the non-clinical range on all CSI subscales. Typically developing children were recruited through contact with neighborhood and community schools, family friends of referred children, and other community resources.

Children with a history of (a) gross neurological, sensory, or motor impairment by parent report, (b) history of a seizure disorder by parent report, (c) psychosis, or (d) Full Scale IQ score less than 85 were excluded from the study. None of the children received medication during the study. Eleven had previously received psychostimulant trials or were currently prescribed psychostimulants but withheld medication for a minimum of $24 \mathrm{~h}$ prior to each testing session. Demographic data for the two groups are provided in Table 1.

\section{Measures}

\section{Working Memory}

The phonological (PH) and visuospatial (VS) working memory tasks used in the current study are identical to those described by Rapport et al. (2008a). Each child was administered four phonological and four visuospatial tasks (i.e., $\mathrm{PH}$ and VS set sizes 3, 4, 5, and 6) across the four testing sessions. The eight working memory set size conditions each contained 24 unique trials of the same stimulus set size, and were counterbalanced across the four testing sessions to control for order effects and potential proactive interference effects across set size conditions (Conway et al. 2005). Five practice trials were administered before each task; children were required to achieve $80 \%$ correct before advancing to the full task (Rapport et al. 2008a). Previous studies of ADHD and typically developing children indicate large magnitude between-group differences on these tasks (Rapport et al. 2008a), and performance on these tasks predict ADHD-related impairments in objectively measured activity level (Rapport et al. 2009) and attentive behavior
Table 1 Sample and demographic variables

\begin{tabular}{|c|c|c|c|c|c|}
\hline \multirow[t]{2}{*}{ Variable } & \multicolumn{2}{|l|}{ ADHD } & \multicolumn{2}{|c|}{$\begin{array}{l}\text { Typically } \\
\text { Developing }\end{array}$} & \multirow[b]{2}{*}{$F(1,39)$} \\
\hline & $\bar{X}$ & $S D$ & $\bar{X}$ & $S D$ & \\
\hline Age & 9.30 & 1.17 & 9.93 & 1.33 & 2.59 \\
\hline FSIQ $^{\mathrm{a}}$ & 103.29 & 13.51 & 110.70 & 10.97 & 3.70 \\
\hline SES & 45.93 & 11.72 & 51.10 & 11.03 & 2.11 \\
\hline \multicolumn{6}{|l|}{ CBCL } \\
\hline AD/HD Problems & 71.38 & 7.07 & 54.80 & 7.91 & $50.15^{* * *}$ \\
\hline \multicolumn{6}{|l|}{ TRF } \\
\hline AD/HD Problems & 66.76 & 7.97 & 54.05 & 4.84 & $37.63 * * *$ \\
\hline \multicolumn{6}{|l|}{ CSI-Parent } \\
\hline ADHD, Combined & 76.52 & 12.04 & 50.10 & 11.68 & $50.80 * * *$ \\
\hline \multicolumn{6}{|l|}{ CSI-Teacher } \\
\hline ADHD, Combined & 64.19 & 9.86 & 49.32 & 7.75 & $28.63 * * *$ \\
\hline CPT Commission Errors & 66.10 & 42.73 & 21.15 & 10.17 & $20.97 * * *$ \\
\hline VMTS Latency (s) & 9.39 & 4.90 & 11.78 & 5.24 & 2.27 \\
\hline VMTS Commission Errors & 38.24 & 14.74 & 22.75 & 13.34 & $12.41 * * *$ \\
\hline
\end{tabular}

CPT and VMTS raw scores are presented here to allow comparison across studies; however, CPT and VMTS impulsivity factor scores were used for all analyses. ADHD $=$ attention-deficit/hyperactivity disorder; $\mathrm{CBCL}=$ Child Behavior Checklist $\mathrm{CPT}=$ Continuous Performance Task; CSI $=$ Child Symptom Inventory severity $T$-scores; FSIQ = Full Scale Intelligence Quotient; SES = socioeconomic status; TRF $=$ Teacher Report Form; VMTS $=$ Visual Match-to-Sample *** $p \leq 0.001$

${ }^{\text {a }}$ Between-group differences in $\mathrm{FSIQ}_{\text {res }}$ were non-significant $(p=0.81$; see Measured Intelligence)

(Kofler et al. 2010). Evidence for reliability and validity of the eight working memory tasks includes high internal consistency $(\alpha=0.82$ to 0.97$)$, and demonstration of the expected magnitude of relationships (Swanson and Kim 2007) with an established measure of short-term memory (WISC-III or -IV Digit Span raw scores: $r=0.50$ to 0.66 ). Performance data (average stimuli correct per trial) were calculated as recommended (Conway et al. 2005).

Phonological (PH) Working Memory Task The phonological working memory task is similar to the Letter-Number Sequencing subtest on the WISC-IV (Wechsler 2003), and assesses phonological working memory based on Baddeley's (2007) model. Children were presented a series of jumbled numbers and a capital letter on a computer monitor. Each number and letter ( $4 \mathrm{~cm}$ height) appeared on the screen for $800 \mathrm{~ms}$, followed by a $200 \mathrm{~ms}$ interstimulus interval. The letter never appeared in the first or last position of the sequence to minimize potential primacy and recency effects, and was counterbalanced across trials to appear an equal number of times in the other serial positions (i.e., position 2, 3, 4, or 5). Children were instructed to recall the numbers in order from smallest to largest, and to say the letter last (e.g., 4 H 62 is 
correctly recalled as $246 \mathrm{H}$ ). Two trained research assistants, shielded from the participant's view, listened to the children's vocalizations through headphones in a separate room and recorded oral responses independently (interrater reliability was $96.2 \%)$.

Visuospatial (VS) Working Memory Task Children were shown nine squares arranged in three offset vertical columns on a computer monitor. A series of $2.5 \mathrm{~cm}$ diameter dots (3, 4,5 , or 6 ) were presented sequentially in one of the nine squares during each trial such that no two dots appeared in the same square on a given trial. All but one dot that was presented within the squares was black; the exception being a red dot that never appeared as the first or last stimulus in the sequence. Children were instructed to indicate the serial position of black dots in the order presented by pressing the corresponding squares on a computer keyboard, and to indicate the serial position of the red dot last.

Estimates of CE, PH, and VS were computed at each set size using the latent variable procedure described by Rapport et al. (2008a) as recommended (Swanson and Kim 2007). Briefly, this process involved regressing the PH and VS working memory tasks onto each other, with shared variance at each set size reflecting the domain-general $\mathrm{CE}$ and unique variance reflecting $\mathrm{PH}$ and VS storage/rehearsal, respectively. Latent factors were created for each construct (CE, PH, VS) using scores at each of the four set sizes.

\section{Behavioral Inhibition}

Stop-Signal Task The stop-signal task and administration instructions are identical to those described by Schachar et al. (2000). Go-stimuli were displayed for $1000 \mathrm{~ms}$ as uppercase letters $\mathrm{X}$ and $\mathrm{O}$ positioned in the center of a computer screen. Xs and Os appeared with equal frequency throughout the experimental blocks. Each go-stimulus was preceded by a dot (i.e., fixation point) displayed in the center of the screen for $500 \mathrm{~ms}$. The fixation point served as an indicator that a go-stimulus was about to appear. A $1000 \mathrm{~Hz}$ auditory tone (i.e., stop-stimulus), was delivered through sounddeadening headphones, and was generated by the computer and presented randomly on $25 \%$ of the experimental trials. Stop-signal delays (SSD) - the latency between presentation of go- and stop-stimuli-was set initially at $250 \mathrm{~ms}$, and adjusted dynamically $\pm 50 \mathrm{~ms}$ contingent on a participant's performance on the previous trial. Successfully inhibited stop-trials were followed by a $50 \mathrm{~ms}$ increase in SSD, and unsuccessfully inhibited stop-trials were followed by a $50 \mathrm{~ms}$ decrease in SSD. The algorithm was designed to approximate successful inhibition on $50 \%$ of the stoptrials. A two-button response box was used wherein the left button was used to respond to the letter $\mathrm{X}$, and the right button was used to respond to the letter O. All participants completed two practice blocks and four consecutive experimental blocks of 32 trials (i.e., 24 go-trials, 8 stop-trials).

Stop-signal reaction time (SSRT) and Stop-signal delay (SSD) were the primary measures of behavioral inhibition in the current study. Both metrics were examined due to disagreement in the literature regarding which variable best captures the behavioral inhibition construct (cf. Alderson et al. 2008; Lipszyc and Schachar 2010). SSRT is unobservable and obtained by subtracting participants' mean SSD from mean reaction time (SSRT = MRT-SSD). Additionally, MRT was included because previous meta-analytic reviews (Alderson et al. 2007) and empirical studies (Alderson et al. 2008) argue that between-group SSRT differences reflect primarily MRT differences as opposed to behavioral inhibition deficits. A latent factor was composed for each BI metric (SSRT, SSD, MRT) separately to remove error and reflect reliable variance associated with each construct across the four blocks.

\section{Impulsivity}

Double-Letter High Density Continuous Performance Task (CPT) The CPT is a laboratory-based measure designed to assess children's sustained attention and impulsivity. A double-letter high target density version of the CPT was selected due to its association with high rates of both omission and commission errors (Denney et al. 2005). The task displayed a total of 540 letters one at a time at a rate of $0.8 \mathrm{~s}$ per letter with an inter-trial interval of $0.2 \mathrm{~s}$ between each letter. The task was comprised of three, 3-min blocks resulting in a total task completion time of approximately $9 \mathrm{~min}$. One-hundred and eighty (33.3\%) of the letters were targets (i.e., double-letters; 90 total responses) and the remaining $360(66.7 \%)$ were non-targets. Participants were instructed to press the left mouse button every time a letter repeated itself and withhold responding to all other letters. The total number of commission errors (i.e., impulsive responding), defined as any non-target stimuli to which the participant responds, was used to compute an impulsivity score for each block. A latent factor reflecting reliable variance associated with the impulsivity construct across the three blocks served as the overall CPT impulsivity score, which correlated 0.57 ( $90 \% \mathrm{CI}=0.40$ to 0.72 ) with CSI parent and teacher ratings of hyperactivity/impulsivity.

Visual Match-to-Sample (VMTS) Task The VMTS task features complex geometric visual and spatial designs and arrangements. Children were shown an abstract visual stimulus (target stimulus) surrounded by eight figures (i.e., seven nearly identical foils and one identical stimulus) and instructed to locate the one exact matching stimulus from the stimulus field as quickly as possible without making errors (see Fig. 1). The figures were each $10 \mathrm{~cm}^{2}$ in size 
and evenly spaced within a $3 \times 3$ configuration such that the total computer screen space measured $41 \mathrm{~cm}$ by $30.5 \mathrm{~cm}$. At the beginning of each trial, children used a track ball to position a small airplane icon inside the red box in the center of the screen to ensure orientation to the target stimuli. A single click anywhere within the center box illuminated the target stimulus and eight surrounding stimuli. The target stimulus was programmed to disappear after $10 \mathrm{~s}$ or after the child made an incorrect response, but could be reilluminated by clicking anywhere within the center stimulus box. An auditory tone was emitted following each correct response. A distinctly different tone followed incorrect responses. Children continued with each trial until they located the correct stimulus for each of the 20 visuospatial trials.

Impulsivity on the VMTS paradigm is reflected by both the speed with which the child responds as well as the number of commission errors the child commits. Faster speeds and higher error rates reflect greater impulsivity. Impulsivity scores were calculated separately for the first and second halves of the task based on recommendations by Salkind and Wright (1977). Specifically, the $z$-score of the average latency to first response was subtracted from the $z$-score of the total number of commission errors to provide an impulsivity score; higher values are indicative of greater impulsivity. A latent factor reflecting reliable variance associated with these impulsivity scores on the first and second halves of the task served as an overall estimate of VMTS impulsivity, which correlated $0.27(90 \% \mathrm{CI}=0.03$ to 0.50$)$ with CSI parent and teacher ratings of hyperactivity/impulsivity.

\section{Measured Intelligence}

All children were administered the Wechsler Intelligence Scale for Children third or fourth edition to obtain an overall estimate of intellectual functioning based on each child's estimated Full Scale IQ (FSIQ; Wechsler 2003). The changeover to the fourth edition was due to its release during the
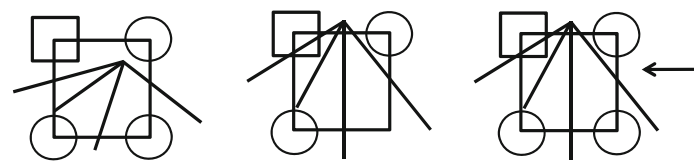

Matching Stimulus
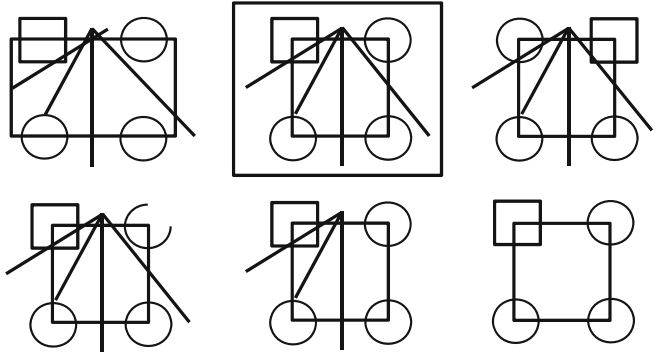

Fig. 1 Visual schematic of one trial taken from the visual match-to-sample tasks (VMTS). Central picture is the target stimulus to be matched to its exact replica among 7 foils. Note: Actual size of each stimulus is $10 \mathrm{~cm}^{2}$ conduct of the study and to provide parents with the most upto-date intellectual evaluation possible. The Full Scale Intelligence Quotient (FSIQ) was not analyzed as a covariate because it shares significant variance with working memory and would result in removing substantial variance associated with working memory from working memory (Ackerman et al. 2005). Instead, a residual FSIQ score was derived using a latent variable approach in which variance shared between the three working memory components (i.e., $\mathrm{CE}, \mathrm{PH}$, and VS) and FSIQ was regressed from FSIQ. The residual FSIQ score (FSIQ ${ }_{\text {res }}$ ) represents IQ that is unrelated to working memory functioning and was examined to evaluate between-group differences in intellectual functioning.

\section{Procedures}

All children participated in four consecutive Saturday assessment sessions. The phonological, visuospatial, stopsignal, CPT, and VMTS tasks were administered as part of a larger battery of laboratory-based tasks that required the child's presence for approximately $2.5 \mathrm{~h}$ per session. All tasks were counterbalanced across testing sessions to minimize order effects. Children completed all tasks while seated alone in an assessment room. All children received brief (2$3 \mathrm{~min}$ ) breaks following each task, and preset longer (10$15 \mathrm{~min}$ ) breaks after every two to three tasks to minimize fatigue. Children were seated approximately $0.66 \mathrm{~m}$ from the computer monitor for all tasks.

\section{Results}

\section{Preliminary Analyses}

All variables were screened for univariate/multivariate outliers and tested against $p<0.001$ (Tabachnick and Fidell 2007). No significant outliers were found. Sample ethnicity was mixed and included 26 white non-Hispanic (63\%), 8 Hispanic English-speaking (20\%), 2 African American (5\%), and 5 children of mixed racial/ethnic background (12\%). All parent and teacher behavior rating scale scores were significantly higher for the ADHD group relative to the TD group as expected (see Table 1). Children with ADHD and TD children did not differ on age $(p=0.12)$, SES $(p=0.15)$, or $\mathrm{FSIQ}_{\text {res }}(p=$ 0.81 ). We therefore report simple model results with no covariates so that B-weights of key pathways can be interpreted as Cohen's $d$ effect sizes (Hayes 2009).

Tier I: Intercorrelations

Intercorrelations between all variables were computed in Tier I of the analyses via bootstrapping ( $90 \%$ confidence intervals) as a first step to determine whether mediation 
analyses were justified. All model-specified variables were interrelated significantly with the exceptions noted below and in Table 2. Models investigating potential, but nonsignificant, mediating pathways (i.e., SSD mediating the diagnostic status/VMTS relationship, MRT mediating the diagnostic status/CPT relationship, and VS Storage/Rehearsal mediating the diagnostic status/VMTS relationship) were not tested because a first-order correlation is expected to exist between a potential mediating variable and the dependent variable prior to entering them into a mediating model (Baron and Kenny 1986).

\section{Tier II: Mediation Analyses}

All analyses were completed utilizing a bias-corrected bootstrapping procedure following the steps recommended by Shrout and Bolger (2002). Bootstrapping was used to estimate and determine the statistical significance of all total, direct, and indirect effects, and is appropriate for total sample sizes as low as 20 (Efron and Tibshirani 1993). All continuous variables were standardized as $z$-scores to facilitate between- and within-model comparisons and allow unstandardized regression coefficients (B-weights) to be interpreted as Cohen's $d$ effect sizes when predicting from a dichotomous grouping variable (Hayes 2009). AMOS version 18.0.2 was used for all analyses, and 5,000 samples were derived from the original sample $(n=41)$ by a process of resampling with replacement (Shrout and Bolger 2002). Only manifest variables were included in the mediation models; therefore, all models are just-identified with perfect fit and no fit statistics are reported.

Separate mediation models were tested to examine the extent to which each of the significantly related Tier I working memory and behavioral inhibition constructs attenuated the relationship between diagnostic group and children's impulsivity scores on the CPT and VMTS. Adopting mediation analysis terminology, the total effect represents the relationship between diagnostic status (ADHD, TD) and children's CPT and VMTS impulsivity scores prior to examining whether hypothesized WM and BI variables serve as significant mediators of these relationships (path $\mathrm{c}$ in Fig. 2 and Tables 3 and 4). In contrast, the direct effects represent the regression coefficients across models for diagnostic status (ADHD, TD) predicting WM (PH storage/ rehearsal, VS storage/rehearsal, central executive) or BI (SSD, SSRT, MRT; path a in Fig. 2 and Tables 3 and 4), as well as each of the WM and BI variables predicting children's CPT and VMTS impulsivity scores (path b in Fig. 2 and Tables 3 and 4). The magnitude of the pathway in which diagnostic status predicts CPT and VMTS impulsivity scores after accounting for the potential mediating influence of WM and BI variables also is considered a direct effect and reported separately (path c' in Fig. 2 and Tables 3 and 4). The residual difference in effect magnitude before (c pathway) and after ( $\mathrm{c}^{\prime}$ pathway) accounting for mediating variables reflects the indirect effect for each of the mediating pathways (path ab in Fig. 2 and Tables 3 and 4).

Effect ratios (indirect effect divided by total effect) were calculated to estimate the proportion of each significant total effect that was attributable to the mediating pathway (indirect effect). Effect ratios were not calculated for models with indirect effect confidence intervals that included 0.0. Confidence intervals containing 0.0 indicate that the magnitude of the indirect effect was not significantly different than zero, and are interpreted as no effect. Except where noted, all confidence intervals reported below were significant and did not contain 0.0 . Cohen's $d$ effect sizes, SE, 90\% confidence intervals, and effect ratios are shown in Tables 3 and 4. $90 \%$ confidence intervals were selected over $95 \%$ confidence intervals because the former are more conservative for evaluating mediating effects (Shrout and Bolger 2002). ${ }^{1}$

\section{Total Effects}

Diagnostic Status and Impulsivity Scores Examination of the total effect (path c) for both tasks revealed that diagnostic status was related significantly to CPT $(d=1.19)$ and VMTS impulsivity scores $(d=0.83)$, indicating large-magnitude increases in CPT and VMTS impulsivity scores for children with ADHD relative to typically developing children (Tables 3 and 4).

\section{Phonological Storage/Rehearsal (PH)}

CPT Impulsivity Diagnostic status exerted a significant direct effect on $\mathrm{PH}$ performance (path a, $d=-0.64$ ), wherein an ADHD diagnosis was associated with lower PH storage/ rehearsal performance. PH storage/rehearsal performance also predicted CPT impulsivity scores (path $\mathrm{b}, \mathrm{B}=-0.39$ ). The B-weight (unstandardized regression coefficient) for path $\mathrm{b}$ is not interpreted as Cohen's $d$ because the predictor is continuous (Hayes 2009).

Examination of the mediation pathway (path ab) revealed that diagnostic status exerted a significant indirect effect on CPT impulsivity scores through its impact on children's PH storage/rehearsal performance $(d=0.25)$. In doing so, it reduced significantly the magnitude of ADHD-related

\footnotetext{
${ }^{1}$ Briefly, the wider $95 \%$ confidence interval increases the likelihood that the confidence interval for $\mathrm{c}^{\prime}$ will include 0.0 , indicating that diagnostic status and impulsivity scores are no longer related significantly after accounting for the mediator (i.e., full mediation in Baron and Kenny [1986] terminology). In contrast, the narrower 90\% confidence interval is less likely to include 0.0 , and therefore is likely to result in a more conservative conclusion regarding the magnitude of the relationship between diagnostic status and impulsivity scores after accounting for the mediator (i.e., partial mediation). For discussion and specific examples of this phenomenon, see Shrout and Bolger (2002).
} 
Table 2 First-order correlations

\begin{tabular}{|c|c|c|c|c|c|c|c|c|c|}
\hline & & 1 & 2 & 3 & 4 & 5 & 6 & 7 & 8 \\
\hline 1. & Diagnostic status & & & & & & & & \\
\hline 2. & PH Storage/Rehearsal & $-0.32 *$ & & & & & & & \\
\hline 3. & VS Storage/Rehearsal & $-0.53 *$ & $-0.30^{*}$ & & & & & & \\
\hline 4. & Central Executive & $-0.73 *$ & $0.61 *$ & $0.57^{*}$ & & & & & \\
\hline 5. & SSRT & $0.61 *$ & $-0.37^{*}$ & $-0.50^{*}$ & $-0.73 *$ & & & & \\
\hline 6. & SSD & $-0.30 *$ & $-0.003, \mathrm{~ns}$ & $0.43^{*}$ & $0.34^{*}$ & $-0.46^{*}$ & & & \\
\hline 7. & MRT & $0.27^{*}$ & $-0.37, \mathrm{~ns}$ & $-0.04, \mathrm{~ns}$ & $-0.35^{*}$ & $0.48^{*}$ & $0.54^{*}$ & & \\
\hline 8. & CPT impulsivity scores & $0.60 *$ & $-0.55^{*}$ & $-0.28^{*}$ & $-0.71^{*}$ & $0.58 *$ & $-0.31^{*}$ & $0.22, \mathrm{~ns}$ & \\
\hline 9. & VMTS impulsivity scores & $0.42 *$ & $-0.43^{*}$ & $-0.09, \mathrm{~ns}$ & $-0.45^{*}$ & $0.31 *$ & $0.01, \mathrm{~ns}$ & $0.31 *$ & $0.46^{*}$ \\
\hline
\end{tabular}

$\mathrm{CPT}=$ Continuous Performance Task MRT $=$ Mean Reaction Time; $\mathrm{PH}=$ phonological $; \mathrm{SSD}=$ Stop-signal delay; SSRT $=$ Stop-signal reaction time; VMTS = Visual Match-to-Sample; VS = visuospatial. * Correlation coefficient is significant based on bootstrapped $90 \%$ confidence intervals that do not include 0.0 (Shrout and Bolger 2002). ns = nonsignificant $(90 \%$ confidence interval includes 0.0$)$.

impulsivity scores on the CPT $(d=1.19$ to 0.94$)$ and accounted for $21 \%$ of the total effect of diagnostic status on CPT impulsivity scores (Table 3).

VMTS Impulsivity $\mathrm{PH}$ performance also exerted a direct effect (path $\mathrm{b}, \mathrm{B}=-0.33$ ) on VMTS impulsivity scores. Examination of the indirect effect (path $\mathrm{ab}, d=0.21$ ) revealed that diagnostic status exerted a significant indirect effect on VMTS impulsivity scores through its impact on PH performance. The total effect of diagnostic status on VMTS impulsivity scores (path c, $d=0.83$ ) was reduced to $d=0.62$ (path $\mathrm{c}^{\prime}$ ) after accounting for the indirect effect of ADHD on VMTS impulsivity scores through PH performance. Calculation of the effect ratio revealed that the indirect effect associated with the mediating $\mathrm{PH}$ pathway accounted for $25 \%$ of the total effect of diagnostic status on VMTS impulsivity scores (Table 4).

\section{Visuospatial Storage/Rehearsal}

CPT Impulsivity Diagnostic status exerted a significant direct effect (path a, $d=-1.04$ ) on VS performance, with ADHD

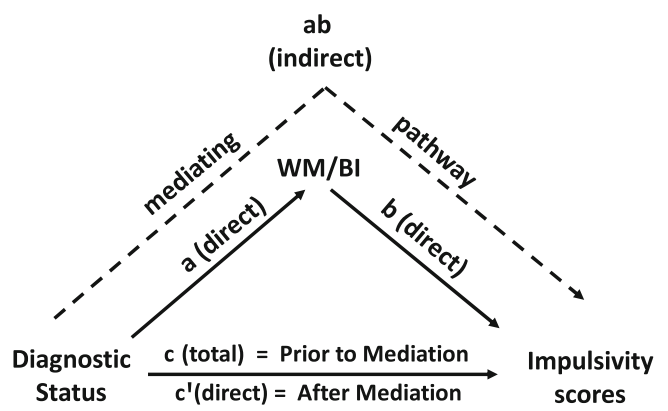

Fig. 2 Visual schematic reflecting the total, direct, and indirect pathways of a bootstrapped mediation analysis before and after accounting for the mediating variable diagnosis associated with lower VS performance. In contrast, VS performance was neither a significant predictor of CPT impulsivity scores (path $\mathrm{b}, n s$ ) nor was it a significant mediator of the relationship between diagnostic status and CPT impulsivity scores $(\mathrm{ab}, n s)$, as the direct and indirect effect confidence intervals both included 0.0 (Table 3 ).

VMTS Impulsivity The potential impact of VS storage/rehearsal on VMTS impulsivity scores was not examined due to the non-significant correlation between these variables in the Tier I analysis.

\section{Central Executive (CE)}

CPT Impulsivity Diagnostic status exerted a direct effect (path a, $d=-1.44$ ) on central executive (CE) performance, with ADHD diagnosis associated with lower CE performance. CE performance also predicted CPT impulsivity scores (path $\mathrm{b}, \mathrm{B}=-0.58$ ). Examination of the indirect (mediation) pathway revealed that diagnostic status exerted a significant indirect effect on CPT impulsivity scores through its impact on children's CE performance (path ab, $d=0.83$ ). In doing so, it reduced the magnitude of ADHD-related deficits in CPT impulsivity scores from $d=1.19$ (path c) to $d=0.36$ (path $\mathrm{c}^{\prime}$, with the $\mathrm{c}^{\prime}$ pathway confidence interval including 0.0 ) and accounted for $70 \%$ of the total effect of diagnostic status on CPT impulsivity scores (Table 3 ).

VMTS Impulsivity CE performance did not exert a direct effect on children's VMTS impulsivity scores (Table 4 path $\mathrm{b}, n s)^{2}{ }^{2}$ Examination of the indirect effect revealed that $\mathrm{CE}$ performance was a significant mediator of the diagnostic status to VMTS impulsivity score relationship (path ab, $d=$

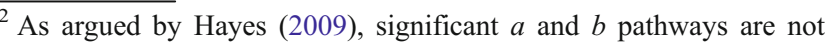
prerequisites for a significant mediating indirect $a b$ effect.
} 
Table 3 Mediation analyses: impact of diagnosis and executive function on CPT impulsivity scores based on between-group Cohen's $d$ effect sizes and standard error $(S E)$

\begin{tabular}{|c|c|c|c|c|c|c|c|c|c|c|}
\hline & & \multicolumn{6}{|c|}{ Working Memory } & \multicolumn{3}{|c|}{ Behavioral Inhibition } \\
\hline \multicolumn{2}{|c|}{ Path } & \multicolumn{2}{|c|}{ PH Storage/Rehearsal } & \multicolumn{2}{|c|}{ VS Storage/Rehearsal } & \multicolumn{2}{|c|}{ Central Executive } & \multicolumn{2}{|l|}{ SSRT } & SSD \\
\hline & Total Effect & d & (SE) & d & (SE) & d & (SE) & d & (SE) & (SE) \\
\hline \multirow[t]{3}{*}{$\mathrm{c}$} & Diagnosis $\rightarrow$ CPT impulsivity scores & $1.19^{*}$ & $(0.25)$ & $1.19^{*}$ & $(0.25)$ & $1.19 *$ & $(0.25)$ & $1.19 *$ & $(0.25)$ & $1.19 * \quad(0.25)$ \\
\hline & $90 \%$ CI of Bootstrap & \multicolumn{2}{|c|}{0.82 to 1.62} & \multicolumn{2}{|c|}{0.82 to 1.62} & \multicolumn{2}{|c|}{0.82 to 1.62} & \multicolumn{2}{|c|}{0.82 to 1.62} & 0.82 to 1.62 \\
\hline & Direct Effects & & & & & & & & & \\
\hline \multirow[t]{2}{*}{$\mathrm{a}$} & Diagnosis $\rightarrow$ EF & $-0.64 *$ & $(0.29)$ & $-1.04 *$ & $(0.27)$ & $-1.44 *$ & $(0.21)$ & $1.20 *$ & $(0.25)$ & $-0.59 * \quad(0.29)$ \\
\hline & $90 \%$ CI of Bootstrap & \multicolumn{2}{|c|}{-1.13 to -0.18} & \multicolumn{2}{|c|}{-1.45 to -0.58} & \multicolumn{2}{|c|}{-1.78 to -1.08} & \multicolumn{2}{|c|}{0.78 to 1.58} & -1.06 to -0.10 \\
\hline \multirow[t]{2}{*}{$\mathrm{b}$} & $\mathrm{EF} \rightarrow \mathrm{CPT}$ impulsivity scores ${ }^{1}$ & $-0.39 *$ & $(0.16)$ & 0.05 & $(0.16)$ & $-0.58^{*}$ & $(0.20)$ & $0.34^{*}$ & $(0.20)$ & $-0.14 \quad(0.16)$ \\
\hline & $90 \%$ CI of Bootstrap & \multicolumn{2}{|c|}{-0.60 to -0.07} & \multicolumn{2}{|c|}{-0.19 to 0.35} & \multicolumn{2}{|c|}{-0.92 to -0.26} & \multicolumn{2}{|c|}{0.02 to 0.67} & -0.42 to 0.11 \\
\hline \multirow[t]{3}{*}{$\mathrm{c}^{\prime}$} & Diagnosis $\rightarrow$ CPT impulsivity scores & $0.94 *$ & $(0.22)$ & $1.24 *$ & $(0.35)$ & 0.36 & $(0.26)$ & $0.78 *$ & $(0.30)$ & $1.10 * \quad(0.26)$ \\
\hline & $90 \%$ CI of Bootstrap & \multicolumn{2}{|c|}{0.59 to 1.33} & \multicolumn{2}{|c|}{0.73 to 1.87} & \multicolumn{2}{|c|}{-0.01 to 0.85} & \multicolumn{2}{|c|}{0.33 to 1.31} & 0.72 to 1.59 \\
\hline & Indirect Effects (through mediator) & & & & & & & & & \\
\hline \multirow[t]{4}{*}{$a b$} & Diagnosis $\rightarrow$ CPT impulsivity scores & & & & & & & & & \\
\hline & Bootstrap Estimate & $0.25^{*}$ & $(0.17)$ & -0.05 & $(0.18)$ & $0.83 *$ & $(0.31)$ & $0.41 *$ & $(0.27)$ & $(0.12)$ \\
\hline & $90 \%$ CI of Bootstrap & \multicolumn{2}{|c|}{0.03 to 0.61} & \multicolumn{2}{|c|}{-0.41 to 0.19} & $0.37 \mathrm{tc}$ & 1.41 & 0.03 to & 0.90 & -0.03 to 0.37 \\
\hline & Effect Ratios & 0.21 & & - & & 0.70 & & 0.34 & & - \\
\hline
\end{tabular}

Bias-corrected bootstrapping was used for all analyses. Paths labels reflect standard nomenclature (cf. Fritz \& MacKinnon 2007) and are depicted in Fig. 2; $\mathrm{c}$ and $\mathrm{c}^{\prime}$ reflect the total and direct effect of Diagnosis on CPT commission errors before and after accounting for working memory or behavioral inhibition, respectively; ${ }^{1}$ Values in the $d$ column for path b do not reflect effect size values due to the use of two continuous variables in the calculation of the direct effect; these values reflect standardized regression $\beta$-weights. CPT = Continuous Performance Task; $d=$ Cohen's $\mathrm{d}$ effect size; $\mathrm{PH}=$ phonological; $S E=$ standard error; $\mathrm{SSD}=$ Stop-signal delay; SSRT $=$ Stop-signal reaction time; VS = visuospatial. $*$ Effect size (or B-weight) is significant based on $90 \%$ confidence intervals that do not include 0.0 (Shrout and Bolger 2002)

0.43). Additionally, CE performance reduced the initial relationship between diagnostic status and VMTS impulsivity from $d=0.83$ (path c) to $d=0.40$ (path $\mathrm{c}^{\prime}$ ) with the $\mathrm{c}^{\prime}$ pathway confidence interval including 0.0 . The effect ratio revealed that $\mathrm{CE}$ performance accounted for $52 \%$ of the total effect of diagnostic status on VMTS impulsivity scores in the model (Table 4).

\section{Stop-Signal Reaction Time (SSRT)}

CPT Impulsivity Diagnostic status exerted a significant direct effect (path a, $d=1.20$ ) on stop-signal reaction time (SSRT), with ADHD diagnosis associated with longer SSRTs. Additionally, SSRT exerted a significant direct effect (path $b, \mathrm{~B}=0.34$ ) on CPT impulsivity scores. Examination of the indirect (mediating) pathway (path ab, $d=0.41$ ) revealed that SSRT was a significant mediator of ADHDrelated impulsivity on the CPT, accounting for $34 \%$ of the total effect.

VMTS Impulsivity Examination of the impact of SSRT on VMTS impulsivity scores revealed that neither the direct effect of SSRT on VMTS impulsivity scores (path b, $n s$ ) nor its inclusion as a potential mediator of the diagnostic status to VMTS impulsivity score relationship (path ab, $n s$ ) were significant as reflected by confidence intervals that included 0.0 (Table 4).

\section{Stop-Signal Delay (SSD)}

CPT Impulsivity Diagnostic status was related significantly to SSD (path a, $d=-0.59$ ), wherein ADHD was associated with shorter SSDs. In contrast, neither the SSD to CPT impulsivity score direct effect (path $\mathrm{b}, n s$ ) nor its inclusion as a potential mediator of the diagnostic status to CPT impulsivity score relationship (path ab, $n s$ ) were significant as the confidence intervals for both relationships included 0.0 (Table 3).

VMTS Impulsivity The potential impact of SSD on VMTS impulsivity scores was not examined due to the nonsignificant correlation between these variables in the Tier I analysis.

\section{Mean Reaction Time (MRT)}

CPT Impulsivity The potential impact of MRT on CPT impulsivity scores was not examined due to the nonsignificant correlation between these two variables found in the Tier I analysis. 
Table 4 Mediation analyses: Impact of diagnosis and executive function on VMTS impulsivity scores based on between-group Cohen's $d$ effect sizes and standard error $(S E)$

\begin{tabular}{|c|c|c|c|c|c|c|c|c|c|}
\hline \multirow[b]{2}{*}{ Path } & & \multicolumn{4}{|c|}{ Working Memory } & \multicolumn{4}{|c|}{ Behavioral Inhibition } \\
\hline & & \multicolumn{2}{|c|}{ PH Storage/Rehearsal } & \multicolumn{2}{|c|}{ Central Executive } & \multicolumn{2}{|l|}{ SSRT } & \multicolumn{2}{|l|}{ MRT } \\
\hline & Total Effect & $d$ & $(S E)$ & $d$ & $(S E)$ & $d$ & $(S E)$ & $d$ & $(S E)$ \\
\hline \multirow[t]{3}{*}{$\mathrm{c}$} & Diagnosis $\rightarrow$ VMTS impulsivity scores & $0.83 *$ & $(0.28)$ & $0.83 *$ & $(0.28)$ & $0.83 *$ & $(0.28)$ & $0.83^{*}$ & $(0.28)$ \\
\hline & $90 \%$ CI of Bootstrap & \multicolumn{2}{|c|}{0.37 to 1.28} & \multicolumn{2}{|c|}{0.37 to 1.28} & \multicolumn{2}{|c|}{0.37 to 1.28} & \multicolumn{2}{|c|}{0.37 to 1.28} \\
\hline & Direct Effects & & & & & & & & \\
\hline \multirow[t]{2}{*}{$\mathrm{a}$} & Diagnosis $\rightarrow \mathrm{EF}$ & $-0.64 *$ & $(0.29)$ & $-1.44 *$ & $(0.21)$ & $1.20^{*}$ & $(0.25)$ & $0.54 *$ & $(0.30)$ \\
\hline & $90 \%$ CI of Bootstrap & \multicolumn{2}{|c|}{-1.13 to -0.18} & \multicolumn{2}{|c|}{-1.78 to -1.08} & \multicolumn{2}{|c|}{0.78 to 1.58} & \multicolumn{2}{|c|}{0.08 to 1.06} \\
\hline \multirow[t]{2}{*}{$\mathrm{b}$} & $\mathrm{EF} \rightarrow$ VMTS impulsivity scores ${ }^{1}$ & $-0.33^{*}$ & $(0.14)$ & -0.30 & $(0.17)$ & 0.08 & $(0.16)$ & 0.21 & $(0.18)$ \\
\hline & $90 \%$ CI of Bootstrap & \multicolumn{2}{|c|}{-0.55 to -0.10} & \multicolumn{2}{|c|}{-0.56 to 0.01} & \multicolumn{2}{|c|}{-0.21 to 0.32} & \multicolumn{2}{|c|}{-0.05 to 0.52} \\
\hline \multirow[t]{3}{*}{$\mathrm{c}^{\prime}$} & Diagnosis $\rightarrow$ VMTS impulsivity scores & $0.62 *$ & $(0.29)$ & 0.40 & $(0.36)$ & $0.74 *$ & $(0.33)$ & $0.72 *$ & $(0.30)$ \\
\hline & $90 \%$ CI of Bootstrap & \multicolumn{2}{|c|}{0.15 to 1.10} & \multicolumn{2}{|c|}{-0.22 to 0.97} & \multicolumn{2}{|c|}{0.19 to 1.28} & \multicolumn{2}{|c|}{0.22 to 1.21} \\
\hline & Indirect Effects (through mediator) & & & & & & & & \\
\hline \multirow[t]{4}{*}{$\mathrm{ab}$} & Diagnosis $\rightarrow$ VMTS impulsivity scores & & & & & & & & \\
\hline & Bootstrap Estimate & $0.21 *$ & $(0.13)$ & $0.43^{*}$ & $(0.26)$ & 0.09 & $(0.20)$ & 0.11 & $(0.10)$ \\
\hline & $90 \%$ CI of Bootstrap & \multicolumn{2}{|c|}{0.05 to 0.47} & \multicolumn{2}{|c|}{0.01 to 0.86} & \multicolumn{2}{|c|}{-0.24 to 0.42} & \multicolumn{2}{|c|}{0.00 to 0.34} \\
\hline & Effect Ratios & \multicolumn{2}{|c|}{0.25} & \multicolumn{2}{|c|}{0.52} & \multicolumn{2}{|l|}{ - } & \multicolumn{2}{|l|}{ - } \\
\hline
\end{tabular}

Bias-corrected bootstrapping was used for all analyses. Paths labels reflect standard nomenclature (cf. Fritz and MacKinnon 2007) and are depicted in Fig. 2; c and c' reflect the total and direct effect of Diagnosis on VMTS commission errors before and after accounting for working memory or behavioral inhibition, respectively; ${ }^{1}$ Values in the $d$ column for path $\mathrm{b}$ do not reflect effect size values due to the use of two continuous variables in the calculation of the direct effect; these values reflect standardized regression $\beta$-weights. $d=$ Cohen's d effect size; MRT = Mean Reaction Time; $\mathrm{PH}=$ phonological; $S E=$ standard error; SSRT $=$ Stop-signal reaction time; VMTS = Visual Match-to-Sample; VS = visuospatial. *Effect size (or B-weight) is significant based on $90 \%$ confidence intervals that do not include 0.0 (Shrout and Bolger 2002)

VMTS Impulsivity Diagnostic status exerted a significant direct effect (path a, $d=0.54$ ) on mean reaction time (MRT), with ADHD diagnosis associated with longer MRTs. In contrast, neither the direct effect of MRT on VMTS impulsivity scores (path $\mathrm{b}, n s$ ) nor its inclusion as a potential mediator of the diagnostic status to VMTS impulsivity score relationship (path ab, ns) was significant as reflected by confidence intervals that included 0.0 .

\section{Tier III: Working Memory and Behavioral Inhibition}

A final series of analyses were undertaken to test predictions from the working memory and behavioral inhibition models regarding the primacy of and interplay between the two executive functions. These mediation analyses were conducted using CPT as the dependent variable because none of the BI metrics mediated between-group differences in VMTS measured impulsivity. Specifically, both working memory variables (CE and PH storage/rehearsal) that mediated ADHD-related CPT impulsivity were regressed onto SSRT (the only BI metric that contributed to ADHD-related CPT impulsivity) and vice versa (SSRT regressed out of CE and $\mathrm{PH}$ ). Residual variance left in each component (i.e., CE without SSRT, SSRT without CE, PH without SSRT, and SSRT without $\mathrm{PH}$ ) was examined as a mediator of the ADHD-CPT impulsivity relationship to determine whether it continued to attenuate ADHD-related impulsivity. After accounting for SSRT, CE continued to exert an indirect effect on ADHD-related impulsivity $(\mathrm{ER}=0.14)$. In contrast, after accounting for CE, SSRT no longer exerted an indirect effect on ADHD-related CPT impulsivity ( $90 \%$ confidence interval included zero). Similarly, after accounting for PH, SSRT no longer exerted an indirect effect on ADHD-related CPT impulsivity. Likewise, PH no longer exerted an indirect effect on ADHD-related CPT impulsivity after accounting for SSRT.

\section{Discussion}

The impulsivity construct has undergone considerable scientific scrutiny over the past several decades and currently is a hallmark feature of two of the three DSM-IV ADHD subtypes (APA 2000). Accumulating evidence indicates that the proclivity to behave impulsively falls along a continuum (Levy et al. 1997), is influenced by genetic and environmental factors, is relatively stable throughout childhood and into adulthood, and predicts multiple adverse long-term outcomes for children with ADHD (Moffitt et al. 2011). In contrast to the plethora of information regarding longitudinal outcomes associated with impulsive behavior, the cognitive processes that may underlie ADHD-related impulsive responding have 
received scant empirical scrutiny. The present study addressed this imparity by testing model-driven predictions of two ADHD executive function models - behavioral inhibition (BI) and working memory (WM) - to determine the extent to which cognitive processes associated with these executive functions mediate the relationship between ADHD status and children's performance on two diverse clinical measures used to assess impulsive responding in an objective manner.

The results were highly consistent with previous investigations demonstrating large magnitude increases in impulsive responding for children with ADHD relative to typically developing children (Cohen's $d$ ES $=0.83$ to 1.19 across tasks). In addition, results revealed that the central executive and phonological storage/rehearsal components of working memory accounted for large and moderate proportions, respectively, of increased ADHD-related impulsivity across tasks. In contrast, visuospatial storage/rehearsal, SSD, and MRT failed to explain between-group differences on either impulsivity task, whereas SSRT partially attenuated between-group impulsivity differences on the CPT but not VMTS. The implications of these findings are discussed below.

Collectively, the PH storage/rehearsal subsystem significantly attenuated the magnitude of ADHD-related CPT and VMTS impulsivity, accounting for $21 \%$ to $25 \%$ of group differences. These findings are consistent with oft-replicated small-to-moderate $\mathrm{PH}$ storage/rehearsal deficits in children with ADHD (Martinussen et al. 2005), and suggest that children with ADHD would show smaller magnitude impairments on these common impulsivity paradigms if not for their phonological storage/rehearsal deficits (Rapport et al. 2008a). The involvement of PH rather than VS storage/rehearsal suggests that the VMTS paradigm's visual stimuli may be too complex to hold in the limited capacity VS storage/rehearsal subsystem for a sufficient duration to conduct a successful search involving sequential evaluation of several visually complex foils. Instead, children appear to rely on the PH subsystem to guide their search by covertly or overtly verbalizing comparative details (e.g., 'this shape's two lines at the bottom are not touching'); a supposition supported by children's anecdotal reports when asked to describe how they located the matching target figure. Overall, this interpretation is consistent with developmental research indicating that children in Western cultures demonstrate increasing reliance on their phonological relative to their visuospatial system for recalling and processing visual information as they mature (Palmer 2000; Pickering 2001).

The central executive (CE) component of working memory was associated with large magnitude decreases in ADHDrelated impulsive responding, such that between-group impulsivity differences on the CPT and VMTS paradigms were no longer detectable after accounting for $\mathrm{CE}$ functioning (i.e., both $90 \%$ ES confidence intervals included 0.0 ). In addition,
CE functioning continued to attenuate between-group impulsivity differences after accounting for the model-implied influence of SSRT behavioral inhibition. The significant and larger contribution of the $\mathrm{CE}$ relative to all other tested executive functions likely reflects the involvement of several processes. For example, both the CPT and VMTS require children to focus attention and maintain relevant stimuli in a highly activated state, monitor ongoing performance, and update memory representations with the presentation of each new stimulus (Shipstead et al. 2010). The large magnitude CE contributions are also consistent with a recent study reporting greater CE relative to subsystem involvement on tasks requiring working memory (Tillman et al. 2011), and suggests that $\mathrm{CE}$ functioning plays a critical role in ADHD-related deficits on tasks traditionally interpreted as measures of impulsivity (Rapport et al. 2001). This pattern of results adds to converging evidence implicating CE impairments in ADHD-related core behavioral symptoms including inattention (Burgess et al. 2010; Kofler et al. 2010) and hyperactivity (Rapport et al. 2009), as well as studies implicating CE deficits in ADHDrelated functional impairments such as peer relationships (Kofler et al. 2011) and time estimation difficulties (Forman et al. 2011).

None of the potential behavioral inhibition indices (i.e., SSRT, SSD, and MRT) were robust predictors of ADHDrelated impulsive responding across both tasks. Specifically, SSD and MRT failed to mediate between-group impulsivity differences on either task, whereas SSRT partially attenuated ADHD-related impulsive responding on the CPT but not VMTS task. In addition, SSRT no longer predicted betweengroup CPT impulsivity differences after accounting for its shared variance with $\mathrm{CE}$ or the $\mathrm{PH}$ storage/rehearsal subsystem. This pattern of results was surprising given that BI and impulsivity were both highly related to diagnostic status. The failure of BI to robustly mediate ADHD-related impulsive responding across tasks suggests that BI and impulsivity are both deficient in children with ADHD, but that deficient BI processes cannot fully account for their impulsive responding. Alternatively, the current study relied exclusively on the stop-signal task, which measures action cancellation, to index BI functioning. Additional research is needed to examine whether other potentially neurologically distinct BI subprocesses such as action restraint contribute to children's impulsive responding (Eagle et al. 2008), and investigate the extent to which $\mathrm{CE}$ functioning accounts for these BI subprocesses.

The results of the present study are consistent with past experimental investigations (Hooks et al. 1994; Inoue et al. 1998; Nigg et al. 1996) and meta-analytic reviews (Frazier et al. 2004; Losier et al. 1996) reporting higher rates of impulsive responding on laboratory-based paradigms in children with ADHD relative to typically developing children. Our findings, however, are inconsistent with studies 
reporting significant relationships between working memory and attention but not hyperactivity/impulsivity in preschool (Brocki et al. 2010; Thorell 2007) and school-aged samples (Lee et al. 2004; Martinussen and Tannock 2006). This discrepancy may reflect fundamental differences in the measurement of WM and impulsivity across studies. For example, previous investigations relied on subjective parent and teacher ratings of hyperactivity/impulsivity, as opposed to the more objective laboratory-based impulsivity paradigms used in the current study. The feasibility of this explanation was examined post hoc by calculating correlations between parent/teacher ratings of hyperactivity/impulsivity $^{3}$ and working memory (PH storage/rehearsal, central executive). The resulting moderate-to-strong correlations between teacher/parent ratings of hyperactivity/impulsivity and WM indices $(r=-0.46$ to -0.59$)$ rendered this explanation unlikely. A more likely explanation involves the measurement of working memory. Specifically, previous studies have relied primarily on digit/location span tasks (forward and backward) to estimate working memory; however, converging experimental evidence reveals that both tasks are measures of short-term memory rather than working memory (Colom et al. 2005; Rosen and Engle 1997; Swanson and Kim 2007), and likely underestimate the significant role of the central executive in impulsive behavior. This conclusion is consistent with recent experimental studies demonstrating that increases in short-term memory demands within the context of working memory tasks have a larger magnitude impact on objective measures of attention (Kofler et al. 2010) relative to objective measures of hyperactivity (Rapport et al. 2009) as well as the current finding of larger central executive relative to storage/rehearsal involvement in impulsive responding.

Results of the final series of analyses revealed that SSRTmeasured behavioral inhibition was no longer significantly associated with ADHD-related impulsive responding on the $\mathrm{CPT}$, whereas CE-related working memory processes continued to attenuate between-group differences after accounting for SSRT. This pattern of results, combined with initial findings that $\mathrm{CE}$ functioning attenuated and $\mathrm{BI}$ failed to attenuate between-group VMTS impulsivity differences, appears to support the WM model prediction that working memory deficits are upstream of BI (Alderson et al. 2010; Rapport et al. 2001; Rapport et al. 2008b), and contradict BI model predictions that $\mathrm{WM}$ deficits are a byproduct of impaired BI processes (Barkley 1997; Barkley 2006). A more likely explanation, however, is that the high percentage of shared variance $\left(R^{2}=0.53\right)$ between these correlated but dissociable executive functions (Garon et al. 2008) reflects

\footnotetext{
${ }^{3}$ The hyperactivity/impulsivity items from the ADHD subscale on the CSI were used and include hyperactivity/impulsivity DSM-IV symptom items similar to those used in the cited studies above.
}

shared processes common to these and other executive functioning tasks. Although the large magnitude $R^{2}$ may have been related partially to our latent method of removing error variance, converging evidence indicates that WM demands reflect a primary feature of complex BI tasks such as the stop-signal used in the current study, and that the CE attentional controller may reflect a higher-order supervisory process common to all executive functions (Garon et al. 2008).

Several caveats warrant consideration when considering the impact of executive functioning deficits, and particularly deficient central executive processes, on impulsive responding by children with ADHD. Independent replication with larger samples that include females, older children, and other ADHD subtypes is needed to address the degree to which our results generalize to the larger ADHD population. Our cell sizes, however, were sufficient based on recommendations in the literature (Efron and Tibshirani 1993; Hsu 1989). It will also be important to examine the extent to which deficient WM processes contribute to other tasks and activities in which decision-making plays an important role, particularly those associated with adverse ADHD-related outcomes such as deficient school work and test scores (Zentall 1993), increased risk for automobile accidents (Barkley 2004), and employment-related difficulties (Barkley et al. 2006). Finally, several children with ADHD participating in the study were comorbid for ODD, however, the comorbidity rate was typical of the ADHD population based on epidemiological findings (i.e., 59\%; Wilens et al. 2002).

The DSM-IV specified core behavioral triad-inattention, hyperactivity, and impulsivity-is associated with multiple near-, intermediate, and long-term adverse outcomes for children with ADHD (APA 2000). Recent evidence indicates that all of these symptoms may reflect the phenotypic expression of deficits in higher-order processes common to specific executive functions including working memory and complex behavioral inhibition (Kofler et al. 2010; Rapport et al. 2009; Sonuga-Barke et al. 2010). If correct, core behavioral symptoms and associated functional impairments of ADHD would be expected to vary according to the environmental (including cognitive) demands placed on the hypothesized substrates (Rapport et al. 2001), and improve to the extent these shared higher-order processes are susceptible to intervention. Nascent efforts aimed at increasing working memory functioning in children with ADHD are promising and associated with small (Holmes et al. 2009) to medium near-term effects (Klingberg et al. 2005) on untrained tasks. These interventions, however, target primarily short-term storage capacity (Gibson et al. 2010), with only incidental training of the higher-order central executive processing deficits identified in the current study. Cognitive training approaches may need to adopt active components that place greater demands on higher-order central executive processes in future investigations to 
determine whether they are susceptible to training and remediation and result in greater magnitude and broader treatment effects.

\section{References}

Achenbach, T. M., \& Rescorla, L. A. (2001). Manual for the ASEBA school-age forms \& profiles. Burlington: University of Vermont Research Center for Children, Youth, \& Families.

Ackerman, P. L., Beier, M. E., \& Boyle, M. O. (2005). Working memory and intelligence: the same or different constructs? Psychological Bulletin, 131, 30-60. doi:10.1037/0033-2909.131.1.30.

Alderson, R. M., Rapport, M. D., \& Kofler, M. J. (2007). AttentionDeficit/Hyperactivity disorder and behavioral inhibition: a metaanalytic review of the stop-signal paradigm. Journal of Abnormal Child Psychology, 35, 745-758. doi:10.1007/s10802-007-9131-6.

Alderson, R. M., Rapport, M. D., Sarver, D. E., \& Kofler, M. J. (2008). ADHD and behavioral inhibition: a re-examination of the stopsignal task. Journal of Abnormal Child Psychology, 36, 989-998. doi:10.1007/s10802-008-9230-z.

Alderson, R. M., Rapport, M. D., Hudec, K. L., Sarver, D. E., \& Kofler, M. J. (2010). Competing core processes in attention-deficit/hyperactivity disorder (ADHD): do working memory deficiencies underlie behavioral inhibition deficits? Journal of Abnormal Child Psychology, 38, 597-507. doi:10.1007/s10802-010-9387-0.

Aman, C. J., Roberts, R. J., Jr., \& Pennington, B. F. (1998). A neuropsychological examination of the underlying deficit in attention deficit hyperactivity disorder: frontal lobe versus right parietal lobe theories. Developmental Psychology, 34, 956-969. doi:10.1037/0012-1649.34.5.956.

American Psychiatric Association. (2000). Diagnostic and statistical manual of mental disorders (4th ed.). Washington: Author.

Aron, A. R., \& Poldrack, R. A. (2005). The cognitive neuroscience of response inhibition: relevance for genetic research in AttentionDeficit/Hyperactivity Disorder. Biological Psychiatry, 57, 12851292. doi:10.1016/j.biopsych.2004.10.026.

Avila, C., Cuenca, I., Félix, V., Parcet, M., \& Miranda, A. (2004). Measuring impulsivity in school-aged boys and examining its relationship with ADHD and ODD ratings. Journal of Abnormal Child Psychology, 32, 295-304. doi:10.1023/B: JACP.0000026143.70832.4b.

Babinski, L. M., Hartsough, C. S., \& Lambert, N. M. (1999). Childhood conduct problems, hyperactivity-impulsivity, and inattention as predictors of adult criminal activity. Journal of Child Psychology and Psychiatry, 40, 347-355. doi:10.1111/1469-7610.00452.

Baddeley, A. (2007). Working memory, thought, and action. New York: Oxford University Press.

Barkley, R. A. (1991). The ecological validity of laboratory and analogue assessment methods of ADHD symptoms. Journal of Abnormal Child Psychology, 19, 149-178. doi:10.1007/BF00909976.

Barkley, R. A. (1997). ADHD and the nature of self-control. New York: Guilford.

Barkley, R. A. (2004). Driving impairments in teens and adults with attention-deficit/hyperactivity disorder. Psychiatry Clinics of North America, 27, 233-260. doi:10.1016/S0193-953X(03) 00091-1.

Barkley, R. A. (2006). Attention deficit hyperactivity disorder: Handbook for diagnosis and treatment (3rd ed.). New York: Guilford.

Barkley, R. A., Fischer, M., Smallish, L., \& Fletcher, K. (2006). Young adult outcome of hyperactive children: adaptive functioning in major life activities. Journal of the American Academy of Child and Adolescent Psychiatry, 45, 192-202. doi:10.1097/01. chi.0000189134.97436.e2.
Baron, R. M., \& Kenny, D. A. (1986). The moderator-mediator variable distinction in social psychological research: conceptual, strategic, and statistical considerations. Journal of Personality and Social Psychology, 51, 1173-1182. doi:10.1037/ 0022-3514.51.6.1173.

Brewis, A. (2002). Social and biological measures of hyperactivity and inattention: are they describing similar underlying constructs of child behavior? Biodemography and Social Biology, 49, 99-115. doi:10.1080/19485565.2002.9989052.

Brocki, K. C., Randall, K. D., Bohlin, G., \& Kerns, K. A. (2008). Working memory in school-aged children with attention-deficit/ hyperactivity disorder combined type: are deficits modality specific and are they independent of impaired inhibitory control? Journal of Clinical and Experimental Neuropsychology, 30, 749-759. doi:10.1080/13803390701754720.

Brocki, K. C., Eninger, L., Thorell, L. B., \& Bohlin, G. (2010). Interrelations between executive function and symptoms of hyperactivity/impulsivity and inattention in preschoolers: a two year longitudinal study. Journal of Abnormal Child Psychology, 38, 163-171. doi:10.1007/s10802-009-9354-9.

Burgess, G. C., Depue, B. E., Ruzic, L., Willcutt, E. G., Du, Y. P., \& Banich, M. T. (2010). Attentional control activation relates to working memory in attention-deficit/hyperactivity disorder. Biological Psychiatry, 67, 632-640. doi:10.1016/j.biopsych. 2009.10.036.

Burns, G. L., \& Walsh, J. A. (2002). The influence of ADHDHyperactivity/Impulsivity symptoms on the development of oppositional defiant disorder symptoms in a 2-year longitudinal study. Journal of Abnormal Child Psychology, 30, 245-256. doi:10.1023/A:1015102812958.

Carlson, C. L., Lahey, B. B., \& Neeper, R. (1986). Direct assessment of the cognitive correlates of attention deficit disorders with and without hyperactivity. Journal of Psychopathology and Behavioral Assessment, 8, 69-86. doi:10.1007/BF00960874.

Colom, R., Abad, F. J., Rebollo, I., \& Shih, P. (2005). Memory span and general intelligence: a latent-variable approach. Intelligence, 33, 623-642. doi:10.1016/j.intell.2005.05.006.

Conway, A. R. A., Kane, M. J., Bunting, M. F., Hambrick, D. Z., Wilhelm, O., \& Engle, R. W. (2005). Working memory span tasks: a methodological review and user's guide. Psychonomic Bulletin \& Review, 12, 769-786. doi:10.3758/ BF03196772.

Denney, C. B., Rapport, M. D., \& Chung, K. (2005). Interactions of task and subject variables among continuous performance tests. Journal of Child Psychology and Psychiatry, 46, 420-435. doi:10.1111/j.1469-7610.2004.00362.x.

Diamantopoulou, S., Rydell, A. M., Thorell, L. B., \& Bohlin, G. (2007). Impact of executive functioning and symptoms of attention deficit hyperactivity disorder on children's peer relations and school performance. Developmental Neuropsychology, 32, 521542. doi:10.1080/87565640701360981.

Eagle, D. M., Bari, A., \& Robbins, T. W. (2008). The neuropsychopharmacology of action inhibition: cross-species translation of the stop-signal and go/no-go tasks. Psychopharmacology, 199, 439456. doi:10.1007/s00213-008-1127-6.

Efron, B., \& Tibshirani, R. (1993). An introduction to the bootstrap. New York: Chapman \& Hall/CRC.

Epstein, J. N., Erkanli, A., Conners, C. K., Klaric, J., Costello, J. E., \& Angold, A. (2003). Relations between continuous performance test performance measures and ADHD behaviors. Journal of Abnormal Child Psychology, 31, 543-554. doi:10.1023/ A:1025405216339.

Forman, H., Mäntylä, T., \& Carelli, M. G. (2011). Time keeping and working memory development in early adolescence: a 4-year follow-up. Journal of Experimental Child Psychology, 108, 170-179. doi:10.1016/j.jecp.2010.07.004. 
Frazier, T. W., Demaree, H. A., \& Youngstrom, E. A. (2004). Metaanalysis of intellectual and neuropsychological test performance in Attention-deficit/Hyperactivity Disorder. Neuropsychology, 18, 543-555. doi:10.1037/0894-4105.18.3.543.

Fritz, M., \& MacKinnon, D. P. (2007). Required sample size to detect the mediated effect. Psychological Science, 18, 233-239. doi:10.1111/j.1467-9280.2007.01882.x.

Gadow, K. D., Sprafkin, J., \& Salisbury, H. (2004). Further validity evidence for the teacher version of the Child Symptom Inventory4. School Psychology Quarterly, 19, 50-71. doi:10.1521/ scpq.19.1.50.29408.

Garon, N., Bryson, S. E., \& Smith, I. M. (2008). Executive function in preschoolers: a review using an integrative framework. Psychological Bulletin, 134, 31-60. doi:10.1037/00332909.134.1.31.

Gibson, B. S., Gondoli, D. M., Files, A. C., Dobrzenski, B. A., \& Unsworth, N. (2010). Application of the dual-component model of working memory to ADHD. Child Neuropsychology, 16, 60 79. doi:10.1080/09297040903146958.

Halperin, J. M., Wolf, L. E., Pascualvaca, D. M., Newcorn, J. H., Healey, J. M., O’Brien, J. D., et al. (1988). Differential assessment of attention and impulsivity in children. Journal of the American Academy of Child and Adolescent Psychiatry, 27, 326-329. doi:10.1097/00004583-198805000-00010.

Halperin, J. M., Sharma, V., Greenblatt, E., \& Schwartz, S. T. (1991). Assessment of the continuous performance test: reliability and validity in a nonreferred sample. Psychological Assessment, 3, 603-608. doi:10.1037/1040-3590.3.4.603.

Hayes, A. F. (2009). Beyond Baron and Kenny: statistical mediation analysis in the new millennium. Communication Monographs, 76, 408-420. doi:10.1080/03637750903310360.

Holmes, J., Gathercole, S. E., \& Dunning, D. L. (2009). Adaptive training leads to sustained enhancement of poor working memory in children. Developmental Science, 12, F9-F15. doi:10.1111/ j.1467-7687.2009.00848.x.

Holmes, J., Gathercole, S. E., Place, M., Alloway, T. P., Elliott, J. G., \& Hilton, K. A. (2010). The diagnostic utility of executive function assessments in the identification of ADHD in children. Child and Adolescent Mental Health, 15, 37-43. doi:10.1111/j.14753588.2009.00536.x

Hooks, K., Milich, R., \& Lorch, E. (1994). Sustained and selective attention in boys with attention deficit hyperactivity disorder. Journal of Clinical Child Psychology, 23, 69-77. doi:10.1207/ s15374424jccp2301_9.

Hsu, L. M. (1989). Random sampling, randomization, and equivalence of contrasted groups in psychotherapy outcome research. Journal of Consulting and Clinical Psychology, 57, 131-137. doi:10.1037/ 0022-006X.57.1.131.

Inoue, K., Nadaoka, T., Oiji, A., Morioka, Y., Totsuka, S., Kanbayashi, Y., et al. (1998). Clinical evaluation of attention-deficit hyperactivity disorder by objective quantitative measures. Child Psychiatry and Human Development, 28, 179-188. doi:10.1023/ A: 1022885827086.

Kaufman, J., Birmaher, B., Brent, D., Rao, U., Flynn, C., Moreci, P., et al. (1997). Schedule for affective disorders and schizophrenia for school-age children-present and lifetime version (K-SADS-PL): initial reliability and validity data. Journal of the American Academy of Child and Adolescent Psychiatry, 36, 980-988. doi:10.1097/ 00004583-199707000-00021.

Klee, S. H., \& Garfinkel, B. D. (1983). The computerized continuous performance task: a new measure of inattention. Journal of Abnormal Child Psychology, 11(4), 487-496. doi:10.1007/ BF00917077.

Klein, C., Wendling, K., Huettner, P., Ruder, H., \& Peper, M. (2006). Intra-subject variability in attention-deficit hyperactivity disorder.
Biological Psychiatry, 60(10), 1088-1097. doi:10.1016/j. biopsych.2006.04.003.

Klingberg, T., Fernell, E., Olesen, P. J., Johnson, M., Gustafsson, P., Dahlström, K., et al. (2005). Computerized training of working memory in children with ADHD-A randomized, controlled trial. Journal of the American Academy of Child and Adolescent Psychiatry, 44, 177-186. doi:10.1097/ 00004583-200502000-00010.

Kofler, M. J., Rapport, M. D., Bolden, J., Sarver, D. E., \& Raiker, J. S. (2010). ADHD and working memory: the impact of central executive deficits and exceeding storage/rehearsal capacity on observed inattentive behavior. Journal of Abnormal Child Psychology, 38, 149-161. doi:10.1007/s10802-009-9357-6.

Kofler, M. J., Rapport, M. D., Bolden, J., Sarver, D. E., Raiker, J. S., \& Alderson, R. (2011). Working memory deficits and social problems in children with ADHD. Journal of Abnormal Child Psychology, 39, 805-817. doi:10.1007/s10802-0119492-8.

Lee, D., Riccio, C. A., \& Hynd, G. W. (2004). The role of executive functions in attention deficit hyperactivity disorder: testing predictions from two models. Canadian Journal of School Psychology, 19, 167-189. doi:10.1177/082957350401900109.

Levy, F., Hay, D. A., McStephen, M., \& Wood, C. (1997). Attentiondeficit hyperactivity disorder: a category or a continuum? Genetic analysis of a large-scale twin study. Journal of the American Academy of Child and Adolescent Psychiatry, 36, 737-744. doi:10.1097/00004583-199706000-00009.

Lipszyc, J., \& Schachar, R. (2010). Inhibitory control and psychopathology: a meta-analysis of studies using the stop signal task. Journal of the International Neuropsychological Society, 16, 1064-1076. doi:10.1017/S1355617710000895.

Losier, B. J., McGrath, P. J., \& Klein, R. M. (1996). Error patterns of the continuous performance test in non-medicated and medicated samples of children with and without ADHD: a meta-analytic review. Journal of Child Psychology and Psychiatry, 37, 971987. doi:10.1111/j.1469-7610.1996.tb01494.x.

Martinussen, R., Hayden, J., Hogg-Johnson, S., \& Tannock, R. (2005). A meta-analysis of working memory impairments in children with attention-deficit/hyperactivity disorder. Journal of the American Academy of Child and Adolescent Psychiatry, 44, 377-384. doi:10.1097/01.chi.0000153228.72591. 73.

Martinussen, R., \& Tannock, R. (2006). Working memory impairments in children with attention-deficit hyperactivity disorder with and without comorbid language learning disorders. Journal of Clinical and Experimental Neuropsychology, 28, 1073-1094. doi:10.1080/13803390500205700.

Moffitt, T. E., Arseneault, L., Belsky, D., Dickson, N., Hancox, R. J., Harrington, H., et al. (2011). A gradient of childhood self-control predicts health, wealth, and public safety. Proceedings of the National Academy of Sciences, 108, 2693-2698. doi:10.1073/ pnas. 1010076108 .

Molina, B. S. G., Smith, B. H., \& Pelham, W. E. (1999). Interactive effects of attention deficit hyperactivity disorder on early adolescent substance use. Psychology of Addictive Behaviors, 13, 348358. doi:10.1037/0893-164X.13.4.348.

Nichols, S. L., \& Waschbusch, D. A. (2004). A review of the validity of laboratory cognitive tasks used to assess symptoms of ADHD. Child Psychiatry and Human Development, 34, 297-315. doi:10.1023/B:CHUD.0000020681.06865.97.

Nigg, J. T., Hinshaw, S. P., \& Halperin, J. M. (1996). Continuous performance test in boys with Attention Deficit Hyperactivity Disorder: Methylphenidate dose response and relations with observed behaviors. Journal of Clinical Child Psychology, 25, 330340. doi:10.1207/s15374424jecp2503 9. 
Nikolas, M. A., \& Burt, S. A. (2010). Genetic and environmental influences on ADHD symptom dimensions of inattention and hyperactivity: a meta-analysis. Journal of Abnormal Psychology, 119, 1-17. doi:10.1037/a0018010.

Olson, S. L., Schilling, E. M., \& Bates, J. E. (1999). Measurement of impulsivity: construct coherence, longitudinal stability, and relationship with externalizing problems in middle childhood and adolescence. Journal of Abnormal Child Psychology, 27, 151165. doi:10.1023/A:1021915615677.

Palili, A., Kolaitis, G., Vassi, I., Veltsista, A., Bakoula, C., \& Gika, A. (2011). Inattention, hyperactivity, impulsivity - epidemiology and correlations: a nationwide Greek study from birth to 18 years. Journal of Child Neurology, 26, 199-204. doi:10.1177/ 0883073810379640.

Palmer, S. (2000). Development of phonological recoding and literacy acquisition: a four-year cross-sequential study. British Journal of Developmental Psychology, 18, 533-555. doi:10.1348/ 026151000165841.

Pickering, S. J. (2001). The development of visuo-spatial working memory. Memory, 9, 423-432. doi:10.1080/09658210143000182.

Rapport, M. D., Loo, S., Isaacs, P., Goya, S., Denney, C. B., \& Scanlan, S. (1996). Methylphenidate and attentional training: comparative effects on behavior and neurocognitive performance in twin girls with attention-deficit/hyperactivity disorder. Behavior Modification, 20, 428-450. doi:10.1177/01454455960204004.

Rapport, M. D., Chung, K. M., Shore, G., \& Isaacs, P. (2001). A conceptual model of child psychopathology: Implications for understanding attention deficit hyperactivity disorder and treatment efficacy. Journal of Clinical Child Psychology, 30, 48-58. doi:10.1207/S15374424JCCP3001_6.

Rapport, M. D., Alderson, R. M., Kofler, M. J., Sarver, D. E., Bolden, J., \& Sims, V. (2008a). Working memory deficits in boys with attention-deficit/hyperactivity disorder (ADHD): the contribution of central executive and subsystem processes. Journal of Abnormal Child Psychology, 36, 825-837. doi:10.1007/s10802-0089215-y.

Rapport, M. D., Kofler, M. J., Alderson, R. M., \& Raiker, J. (2008b). Attention-deficit/hyperactivity disorder. In M. Hersen \& D. Reitman (Eds.), Handbook of psychological assessment, case conceptualization and treatment, volume 2: Children and adolescents (pp. 125-157). NJ: Wiley \& Sons.

Rapport, M. D., Bolden, J., Kofler, M. J., Sarver, D. E., Raiker, J. S., \& Alderson, R. M. (2009). Hyperactivity in boys with attentiondeficit/hyperactivity disorder (ADHD): a ubiquitous core symptom or manifestation of working memory deficits? Journal of Abnormal Child Psychology, 37, 521-534. doi:10.1007/s10802008-9287-8.

Rodriguez, D., Tercyak, K. P., \& Audrain-McGovern, J. (2008). Effects of inattention and hyperactivity/impulsivity symptoms on development of nicotine dependence from mid adolescence to young adulthood. Journal of Pediatric Psychology, 33, 563575. doi:10.1093/jpepsy/jsm100.

Rosen, V. M., \& Engle, R. W. (1997). Forward and backward serial recall. Intelligence, 25, 37-47. doi:10.1016/S0160-2896(97) 90006-4.
Salkind, N. J., \& Wright, J. C. (1977). The development of reflectionimpulsivity and cognitive efficiency: an integrated model. Human Development, 20, 377-387. doi:10.1159/000271569.

Schachar, R., Mota, V., Logan, G., Tannock, R., \& Klim, P. (2000). Confirmation of an inhibitory control deficit in attention-deficit/ hyperactivity disorder. Journal of Abnormal Child Psychology, 28, 227-235. doi:10.1023/A:1005140103162.

Sergeant, J. A., Geurts, H., \& Oosterlaan, J. (2002). How specific is a deficit of executive functioning for Attention-Deficit/Hyperactivity Disorder. Behavioural Brain Research, 130, 3-28. doi:10.1016/ S0166-4328(01)00430-2.

Shipstead, Z., Redick, T. S., \& Engle, R. W. (2010). Does working memory training generalize? Psychologica Belgica, 50(3-4), 245-276. Retrieved from EBSCOhost.

Shrout, P. E., \& Bolger, N. (2002). Mediation in experimental and nonexperimental studies: new procedures and recommendations. Psychological Methods, 7, 422-445. doi:10.1037/1082-989X. 7.4.422.

Sonuga-Barke, E., Bitsakou, P., \& Thompson, M. (2010). Beyond the dual pathway model: evidence for the dissociation of timing, inhibitory, and delay-related impairments in attention-deficit/hyperactivity disorder. Journal of the American Academy of Child and Adolescent Psychiatry, 49, 345-355. doi:10.1097/00004583201004000-00009.

Swanson, H. L., \& Kim, K. (2007). Working memory, short-term memory, and naming speed as predictors of children's mathematical performance. Intelligence, 35, 151-168. doi:10.1016/j. intell.2006.07.001.

Tabachnick, B. G., \& Fidell, L. S. (2007). Using multivariate statistics (5th ed.). Boston: Allyn \& Bacon/Pearson Education.

Thorell, L. B. (2007). Do delay aversion and executive function deficits make distinct contributions to the functional impact of ADHD symptoms? A study of early academic skill deficits. Journal of Child Psychology and Psychiatry, 48, 1061-1070. doi:10.1111/ j.1469-7610.2007.01777.x.

Tillman, C., Eninger, L., Forssman, L., \& Bohlin, G. (2011). The relation between working memory components and ADHD symptoms from a developmental perspective. Developmental Neuropsychology, 36, 181-198. doi:10.1080/87565641.2010.549981.

Wechsler, D. (2003). Wechsler intelligence scale for children-fourth edition. San Antonio: Psychological Corporation.

Wilens, T. E., Biederman, J., Brown, S., Tanguay, S., Monuteaux, M. C., Blake, C., et al. (2002). Psychiatric comorbidity and functioning in clinically referred preschool children and schoolage youths with ADHD. Journal of the American Academy of Child and Adolescent Psychiatry, 41, 262-268. doi:10.1097/ 00004583-200203000-00005.

Willcutt, E. G., Doyle, A. E., Nigg, J. T., Faraone, S. V., \& Pennington, B. F. (2005). Validity of the executive function theory of attention-deficit/hyperactivity disorder: a meta-analytic review. Biological Psychiatry, 57, 1336-1346. doi:10.1016/j.biopsych. 2005.02.006.

Zentall, S. S. (1993). Research on the educational implications of attention deficit hyperactivity disorder. Exceptional Children, 60, 143-154. 